\title{
Análise de necessidades no Ensino Médio Integrado em informática do Instituto Federal do Acre $^{1}$
}

...Pedras no caminho? Guardo todas, um dia vou construir um castelo...

Mário Quintana

Cristiane das Neves
Universidade Estadual Paulista “Júlio de Mesquita Filho" (UNESP),
São José do Rio Preto, São Paulo, Brasil.
cristianeneves.unesp@gmail.com
https://orcid.org/0000-0003-1589-9656

DOI: http://dx.doi.org/10.21165/el.v47i2.2036

\section{Resumo}

Este artigo tem o objetivo de apresentar uma experiência de análise de necessidades para a aprendizagem de inglês realizada com 100 alunos, sete professores e três informantes especialistas. A análise conduzida visou identificar o perfil dos alunos e a situação-alvo para o ensino de língua inglesa em um curso de Ensino Médio Integrado em Informática de um Instituto Federal de Educação, Ciência e Tecnologia. O arcabouço teórico que embasou o processo foi de Hutchinson e Waters (1987), Jordan (1997), Dudley-Evans e St. John (1998), Ramos (2004), Aranha (2009), Vieira e Aranha (2015), Rossini e Belmonte (2015). Os dados foram obtidos através de questionários on-line, entrevistas semiestruturadas e consulta aos documentos que norteiam o curso integrado. Os resultados apontam o caminho para os gêneros que circulam na comunidade discursiva (SWALES, 1990) dos programadores.

Palavras-chave: ensino médio integrado; inglês para fins específicos; análise de necessidades.

Needs analysis in High School integrated to Vocational Course in Computing at the Federal Institute of Acre

\begin{abstract}
The objective of this article is to describe a needs analysis experience to the learning of English held with 100 students, seven teachers and three experts. The analysis was conducted with the aim of identifying the students profile and the target situation for the teaching of English in a High School Course integrated to Vocational on Computing from a Federal Institute of Education, Science and Technology. The research had Hutchinson and Waters (1987), Jordan (1997), Dudley-Evans and St. John (1998), Ramos (2004), Aranha (2009), Vieira and Aranha (2015), Rossini and Belmonte (2015) for the theoretical background. The instruments used for collecting data were online questionnaires, semi structured interviews and the consultation of guiding documents for the integrated courses. Results point at the genres of the discursive community (SWALES, 1990) of the computer programmers.
\end{abstract}

Keywords: high school integrated to vocational course; english for specific purposes; needs analysis.

\footnotetext{
${ }^{1}$ Agradeço a disposição da pesquisadora Bruna Gabriela Augusto Marçal Vieira em ler e contribuir com observações para $\mathrm{o}$ artigo.
} 


\section{Introdução}

Os cursos de Ensino Médio Integrado nos Institutos Federais têm uma natureza peculiar, pois buscam formar os alunos tanto no ensino básico geral quanto na educação profissional técnica de nível médio, com vistas a preparar os aprendizes para que sejam capazes de refletir sobre os problemas da área profissional em diferentes dimensões. A aprendizagem de uma língua estrangeira nesta conjuntura pode inserir-se no contexto do ensino de Línguas para Fins Específicos (LinFE).

Cursos em LinFE trabalham o ensino e aprendizagem da língua estrangeira para atender às necessidades específicas de quem precisa usar a língua em uma situação de trabalho ou acadêmica. Nesse contexto, o gênero tem sido considerado como central para o ensino especializado de língua e no desenvolvimento de habilidades profissionais (SWALES, 2004). Pressupõe-se, ainda, a proposição de um syllabus para especificar o que será ensinado em um curso instrumental de língua, e estabelecer os objetivos de aprendizagem. O syllabus é desenvolvido com base nos gêneros relevantes para o público-alvo, e, portanto, o primeiro passo para o desenvolvimento de um curso de LinFE é a Análise de Necessidades (AN) (HUTCHINSON; WATERS, 1987; JORDAN, 1997; DUDLEY-EVANS; ST. JOHN, 1998; VIEIRA; ARANHA, 2015), pela qual identificam-se os gêneros, as habilidades e os conhecimentos que os alunos precisam desenvolver para utilizá-los.

Este artigo propõe compartilhar uma fase do processo da AN realizada no contexto do Ensino Médio Integrado em Informática (EMII) do Instituto Federal do Acre (IFAC), campus Rio Branco, curso que forma técnicos para atuar em manutenção de computadores e programação. A análise - cujo objetivo era investigar, através do levantamento da situação-alvo e do perfil dos alunos, se o que a disciplina de inglês oferece atende às necessidades da formação profissional requerida pelo Ensino Médio Integrado - foi realizada em quatro etapas, a saber: (i) aplicação de um questionário online via Google docs a 100 alunos das turmas do primeiro ao quarto ano do referido curso; (ii) aplicação de um questionário a sete professores das disciplinas técnicas dessas turmas; (iii) realização de entrevistas com especialistas, ou seja, profissionais da área de informática de empresas da cidade de Rio Branco; (iv) duas entrevistas para dirimir dúvidas, uma com alguns alunos e outra com um professor; e (v) consulta aos documentos norteadores.

O presente trabalho pretende contribuir com pesquisas em análise de necessidades de aprendizagem de língua estrangeira em cursos integrados através da investigação do contexto de ensino em um campus do Instituto Federal no Acre.

\section{Fundamentação teórica}

\section{Ensino Médio Integrado e as línguas estrangeiras}

Frigotto, Ciavatta e Ramos (2012) qualificam o Ensino Médio Integrado como "uma proposta de 'travessia' imposta pela realidade de milhares de jovens que têm direito ao ensino médio pleno e, ao mesmo tempo, necessitam se situar no sistema produtivo". O Ensino Médio articulado e integrado "a uma formação científico- 
tecnológica e ao conhecimento histórico social" devem permitir que o jovem compreenda os "fundamentos técnicos, sociais, culturais e políticos do atual sistema produtivo" (FRIGOTTO; CIAVATTA; RAMOS, 2012, p. 15).

Neste viés, ao refletir o ensino de línguas no Ensino Médio na concepção de integração, Zolin-Vesz e Souza (2010) compreendem que esse deve possibilitar ao aluno "estudar os problemas de uma área profissional em suas múltiplas dimensões, tais como econômica, social, política, cultural e técnica". Os autores afirmam, à luz dos textos nos documentos oficiais que norteiam o Ensino Médio, que o objetivo das línguas estrangeiras em um Ensino Médio que tem a finalidade de profissionalizar é não somente adquirir conhecimentos de estratégias de leitura, mas também ser capaz de compreender discursos sobre "aspectos sócio-políticos" do mundo do trabalho produzidos na língua alvo (ZOLIN-VESZ; SOUZA, 2010, p. 2).

Enfatizando o posicionamento dos autores, pode-se referir ao Parecer CNE/CEB 11/2012, que foi base para a Resolução 6/2012, uma vez que assevera que a Educação Profissional deve ultrapassar o "domínio operacional de um determinado fazer", proporcionando uma "compreensão global do processo produtivo, com a apreensão do saber tecnológico, a valorização da cultura do trabalho e a mobilização dos valores necessários à tomada de decisões no mundo do trabalho" (BRASIL, 2012a, p. 8). Os sujeitos envolvidos em um processo de aprendizagem na Educação Profissional devem ser capazes de gerenciar suas vidas produtivas e de agir em seu próprio benefício diante dos desafios da articulação entre trabalhadores e empregadores. Devem ser cidadãos autônomos e críticos, com capacidade de, permanentemente, se adaptar às exigências do mundo do trabalho.

O ensino via gêneros propicia explorar os desafios que os sujeitos deverão enfrentar, preparando-os para o trabalho. Corroborando, Ramos (2004) enfatiza que é importante analisar e se familiarizar com o gênero para o ensino. Os gêneros textuais propiciam condições de "levantar o que os alunos têm de fazer linguisticamente", quais discursos eles têm de ser capazes de "compreender e produzir nas modalidades escrita ou falada". Os gêneros textuais são um recurso "poderoso" que possibilita, ainda, que o professor considere o propósito, o contexto de situação e de cultura de um texto para compreendê-lo (RAMOS, 2004, p. 116).

\section{Línguas para Fins Específicos}

Segundo Rossini e Belmonte (2015), a abordagem de LinFE teve início no Brasil na década de 70 com o ensino de francês. Posteriormente, o Projeto Nacional Ensino de Inglês Instrumental em Universidades Brasileiras surgiu para atender a uma demanda de professores de inglês em departamentos de ciências puras e aplicadas. Havia um interesse dos professores em se prepararem para oferecer cursos na área de LinFE (ROSSINI; BELMONTE, 2015). Cursos em LinFE têm o objetivo de atender às demandas específicas de um aprendiz ou um grupo de aprendizes relativas ao uso de determinada língua. 
O ensino de Inglês para Fins Específicos (IFE) ou English for Specific Purposes (ESP) é uma subcategoria de LinFE. Pesquisadores em ESP iniciaram o uso da análise de gêneros "como ferramenta pedagógica e de pesquisa" nos anos 80 , porém, foi a obra de John Swales que ofereceu uma metodologia para a introdução da "análise de gêneros na pesquisa e ensino de ESP” (BAWARSHI; JO REIFF, 2013, p. 61).

Swales define gênero como uma classe de eventos comunicativos, uma situação constituída de discurso verbal, na qual é, fundamentalmente, utilizada a linguagem. Os eventos compartilham de um propósito comunicativo, ou seja, o objetivo da comunicação. O gênero pode ser identificado a partir de traços semelhantes, que Swales chama de prototipicidade. Outro conceito da sua teoria é o de comunidade discursiva, definida como o conjunto dos membros que reconhecem os gêneros que circulam em determinados contextos, e que os utilizam para a realização de objetivos partilhados. O trabalho de Swales, conforme afirmam Hemais e Biasi-Rodrigues (2005, p. 108), é voltado para a aplicação "em análises de gêneros textuais em contextos acadêmicos e profissionais", esclarecendo o gênero e as práticas sociais subjacentes, facilitando a aprendizagem sobre os gêneros e o modo como compreendê-los e produzi-los.

Portanto, a fim de identificar quais gêneros fazem parte do repertório do ambiente profissional em que os aprendizes do Ensino Médio Integrado em Informática serão inseridos após sua formação, a Análise de Necessidades é apresentada como alternativa fundamental no processo de levantamento da situação-alvo.

\section{Análise de Necessidades (AN)}

Richards et al. (1992) apud Jordan (1997) definem análise de necessidades como a ação de determinar para quê um aprendiz ou um grupo de aprendizes precisa de uma língua e ordenar as necessidades por prioridades, incluindo informações subjetivas e objetivas. Para Dudley-Evans e St. John (1998), é estabelecer "o quê" e o "como" de um curso. Haque (2014) afirma que a análise de necessidades é importante para que um professor tenha informações precisas sobre seus aprendizes, reduzindo as lacunas entre professores, aprendizes e materiais. A análise de necessidades, para Dudley-Evans e St. John (1998), direciona o curso para seu foco. De acordo com Hutchinson e Waters (1987), a diferença entre aprendizes de um curso de inglês geral e de inglês para fins específicos é a consciência da sua necessidade. Os autores sugerem pensar em termos de necessidades, lacunas e desejos para a situação-alvo.

As necessidades são definidas por Hutchinson e Waters (1987, p. 55) por serem o que o aprendiz precisa saber para agir na situação-alvo, ou seja, "as características linguísticas - discursivas, funcionais, estruturais e lexicais" que serão usadas no contexto. Lacuna é definida como a diferença entre o que o aprendiz sabe e o que ele precisa saber para a situação-alvo; já os desejos são o que eles percebem que necessitam ou querem aprender. Segundo os autores, os desejos dos aprendizes não têm necessariamente uma relação com o que os professores ou responsáveis pelo curso consideram que eles devem aprender.

A condução da AN realizada para o curso do EMII teve o objetivo de identificar as características da situação-alvo e os desejos e as percepções dos próprios aprendizes das suas necessidades. Os professores indicaram as suas percepções com relação à necessidade de aprendizagem de inglês dos seus alunos e os profissionais da área de 
informática colaboraram com a informação das situações que os egressos terão de lidar no ambiente de trabalho.

Com relação aos métodos de coletas de dados, Jordan (1997) relaciona quatorze possibilidades, entre elas, questionários, entrevistas, testes, monitoramento/observação, pesquisa anterior, investigação posterior, estudo de caso, auto avaliação, documentação. Para esta fase inicial da análise descrita neste artigo, foram utilizados questionários online para os alunos e professores, pela facilidade na coleta e apuração dos dados. A entrevista semiestruturada, agendada no local de trabalho dos consultores técnicos, nesse caso, mostrou-se mais adequada por propiciar a flexibilidade de poder dirimir dúvidas imediatamente. Além disso, possibilitou explorar um ambiente mais desconhecido pela pesquisadora do que o dos alunos, através de perguntas mais livres e devido ao número pequeno de sujeitos. O último método foi a análise dos documentos que norteiam a forma articulada de Ensino Médio e Educação Profissional, esclarecendo as orientações nacionais e institucionais para esse contexto.

\section{Metodologia}

\section{Contexto da pesquisa}

De 1909 a 2002, foram criadas 140 escolas técnicas federais; entre 2005 e 2010, foram acrescidas 202 escolas, 126 campi e unidades universitárias e houve aumento de 148\% nas matrículas (BRASIL, 2010). Um crescimento significativo em termos de estrutura física, professores contratados e alunos matriculados, em cinco anos, pois, através da Lei $11.892 / 2008^{2}$ foram criados os Institutos Federais de Educação, Ciência e Tecnologia mediante integração entre Centros Federais de Educação Tecnológica e Escolas Técnicas Federais em alguns Estados, em outros, mediante transformação das Escolas ou Centros. Os Institutos oferecem educação profissional técnica de nível médio e tecnológica de nível superior, com a obrigatoriedade de priorizar a oferta de cursos de ensino médio integrado, nas modalidades regular e de educação de jovens e adultos.

O Acre participa desses números uma vez que a Escola Técnica Federal criada em 2009 se torna Instituto Federal do Acre em 2010. A estrutura ainda estava em organização em 2016, quando a pesquisa foi realizada, com documentos institucionais sendo produzidos e as ocupações de cargos enfrentando certa rotatividade de pessoas, devido, em parte, à grande demanda por qualificação. O Ensino Médio Integrado, prioridade da Rede Federal, tal como seus alunos adolescentes e a própria instituição, é um "ente" em pleno desenvolvimento e formação.

O curso de Ensino Médio Integrado em Informática (EMII), contexto específico de realização dessa pesquisa, teve sua primeira turma em 2011. O Projeto Pedagógico do Curso passou por várias reformulações na tentativa de adequar disciplinas, cargas horárias e as condições do instituto ainda em estruturação. Apesar de a proposta ser de integração e interdisciplinaridade, as disciplinas são dispostas de forma linear e sequencial, os conteúdos das disciplinas básicas são definidos prioritariamente atendendo à formação geral.

\footnotetext{
${ }^{2}$ Lei no 11.892 , de 29 de dezembro de 2008. Institui a Rede Federal de Educação Profissional, Científica e Tecnológica, cria os Institutos Federais de Educação, Ciência e Tecnologia.
} 
Com a finalidade de contribuir com a estruturação da disciplina de Língua Inglesa, foi conduzida a Análise de Necessidades, sendo descrito o levantamento da situação-alvo neste trabalho realizado a partir da percepção de todos os sujeitos envolvidos na comunidade discursiva, os profissionais de informática, os alunos, professores e instituição por meio de seus documentos oficiais.

\section{Participantes}

Visando contribuir para a compreensão da necessidade na situação-alvo, os profissionais escolhidos como informantes especialistas, identificados como Consultores Técnicos I, II e III, foram: CTI, Assistente de Suporte de TI em empresa nacional com representação e administração regional; CTII trabalha no setor de Tecnologia e Inteligência de um órgão público estadual e CTIII é do setor de Tecnologia de empresa pública estadual. Todos com mais de dez anos de profissão na área de informática, trabalhando com manutenção de sistemas e programação.

Os professores foram escolhidos, inicialmente, a partir da observação das ementas das disciplinas, considerando se elas adotavam ou não títulos em inglês na sua bibliografia. Ao acessar as ementas anexadas ao plano de curso, constatou-se que apenas uma das disciplinas, com exceção de Língua Inglesa, apresentava um título em inglês na sua bibliografia.

A opção, então, foi escolher as que tinham ao menos uma palavra ou temática que pudesse levar à língua inglesa, tais como hardware, software. Dessa forma, sete professores foram convidados das disciplinas de Banco de Dados, Engenharia de Software, Sistemas Operacionais e Aplicativos, Lógica de Programação, Hardware, Programação WEB e Redes de Computadores. Todos aceitaram participar da pesquisa, responderam a um questionário sobre suas percepções em relação à necessidade de conhecimento da língua inglesa dos aprendizes.

Todos os alunos das cinco turmas, do primeiro ao quarto ano, do EMII do campus Rio Branco do IFAC, foram escolhidos para responder aos questionários. Em torno de 120 alunos foram convidados, com 100 respostas obtidas, destarte, aproximadamente $83 \%$ contribuíram com a pesquisa. Foram convidados todos os estudantes por representar um número relativamente pequeno para administrar em termos de respostas ao questionário, e por ser importante a opinião da maior quantidade possível de alunos. Foi elaborado um questionário direcionado para o levantamento de suas experiências anteriores e suas próprias percepções em relação à necessidade de aprendizagem do inglês.

O projeto para a presente pesquisa obedeceu aos trâmites éticos exigidos, sendo aprovado pelo Comitê de Ética em Pesquisa da Universidade Estadual Paulista, sob o processo CAAE: 60765416.6.0000.5466 e parecer de número 1.795.138. Os termos de consentimento livre e esclarecido foram assinados pelos responsáveis pelos menores, professores e profissionais informantes. Os alunos assinaram termo de assentimento livre e esclarecido. 


\section{Instrumentos de pesquisa}

Os questionamentos que introduziram as entrevistas com os consultores técnicos foram sobre se havia a utilização da língua inglesa na rotina de trabalho, com qual frequência e para quê, e quais dificuldades ou facilidades eram encontradas nesses contextos; outro objetivo da entrevista foi definir características da comunidade discursiva dos profissionais de informática.

A consulta aos documentos de base nacional (LDB, Resolução 6/2012, Parecer 11/2012) e local (Projeto Pedagógico do Curso e Ementa da Disciplina), teve o objetivo de compreender as orientações e finalidades para a disciplina de língua estrangeira no curso de Ensino Médio Integrado. Contribuindo com a análise de necessidades (HUTCHINSON; WATERS, 1987; JORDAN, 1997; DUDLEY-EVANS; ST. JOHN, 1998) juntamente com o resultado dos questionários e das entrevistas com um professor e alguns alunos.

O questionário on-line, elaborado via Formulários Google, foi o instrumento utilizado com o grupo de professores, com dez perguntas fechadas e duas abertas. O questionário procurou saber o quanto os docentes (i) utilizam materiais em inglês em suas aulas e quais são eles; (ii) a importância que dão ao conhecimento de inglês do aluno e para que ele deve saber inglês; (iii) como avaliam o conhecimento dos seus alunos nas habilidades, técnicas e estratégias de uso da língua.

Um questionário, também elaborado via Formulários Google com 13 perguntas fechadas e duas abertas aplicado aos alunos, foi utilizado por viabilizar a coleta de dados de um grande número de sujeitos de forma ágil. Perguntas com o mesmo objetivo serviram para o cruzamento de dados (RAMOS, 2004). A finalidade foi levantar, a partir das respostas dos alunos ao questionário, (i) a experiência com a aprendizagem do inglês, prévia ao ingresso no curso de EMII; (ii) uso do inglês no cotidiano e para quê; (iii) auto avaliação nas quatro habilidades, que são: leitura, escrita, compreensão auditiva e fala; (iv) importância dada à aprendizagem do inglês; (v) reconhecimento das habilidades, técnicas e estratégias necessárias às atividades que julgam importante; e (vi) auto avaliar os conhecimentos nas habilidades, técnicas e estratégias. Ambos os grupos, alunos e professores, puderam opinar livremente em uma questão aberta sobre suas sugestões para colaborar com a disciplina de inglês.

\section{Análise dos dados}

\section{Entrevistas com profissionais da Informática}

As entrevistas com os consultores técnicos tiveram o objetivo de dar indícios das características da comunidade discursiva dos técnicos em informática e esclarecer a situação-alvo, guiadas pela pergunta: para que o técnico em informática utiliza a língua inglesa na sua rotina de trabalho? Como técnico, CTI não utiliza muito o inglês, somente termos técnicos, pois não exerce a função de programador na empresa e acessa, em maior parte, material em português no ambiente de trabalho. Todavia, reconhece a necessidade do inglês para quem programa. CTII confirma que utiliza bastante o inglês e que para desempenhar suas tarefas diárias recorre a termos técnicos e estratégias de 
leitura com facilidade. CTIII afirma que utiliza muito o inglês para leitura de manuais, para programar e em eventuais chats com técnicos no exterior para dirimir alguma dúvida.

Sobre as possíveis dificuldades encontradas pelos profissionais com a língua, CTIII, que é egresso de um curso superior tecnológico em Sistemas para Internet de instituição federal, contou que, depois de formado, ele e outros colegas de trabalho contrataram um professor de inglês para ensinar-lhes "gramática". Afirma considerar importante saber a função das palavras para ser capaz de compreender um texto. Faz-se necessário aprimorar a compreensão do uso da gramática para o ensino dos gêneros utilizados pelos profissionais.

Tais respostas enfatizam que a língua inglesa é fundamental para o profissional da programação e, então, o objetivo principal da disciplina de inglês em um curso de EMII deve ser oferecer os subsídios necessários para o preparo para a vida profissional. Em busca de reconhecer os gêneros utilizados na área, foi solicitado aos consultores que fornecessem exemplares. CTII, durante sua entrevista, mencionou a documentação, e apresentou alguns exemplos on-line do que ele reconhece como tal e que utiliza com muita frequência. Em Engenharia de Software, Brookshear (2013) é um dos teóricos que define os tipos de documentação. A título de exemplificação, a documentação de sistema tem o propósito de "descrever a composição interna, de forma que o sistema possa ser mantido posteriormente em seu ciclo de vida" (BROOKSHEAR, 2013, p. 295). Vislumbramos aqui o caminho para os gêneros que fazem parte do repertório do profissional de programação.

Outro questionamento era sobre as formas de comunicação entre os programadores para auxiliar no reconhecimento da comunidade discursiva dos profissionais de programação, pois esta pressupõe um objetivo compartilhado e um reconhecimento da linguagem específica dos membros, "ou seja, as expectativas, vontades, crenças e ideologias que regem seu discurso e os gêneros utilizados" (VIEIRA; ARANHA, 2015, p. 50). CTI alerta para o fato de que os profissionais que atuam na área de informática não possuem um conselho de classe profissional, dessa forma, não há uma organização que regulamente a atuação do trabalhador. Assim, qualquer pessoa que tenha algum conhecimento específico da área, segundo ele, identificado pela linguagem utilizada que define o meio, pode se autodenominar um técnico e oferecer seus serviços, dispensando formação institucional para este fim. Muitos trabalhadores são autodidatas e, a depender de seus clientes ou cargos, não necessitam apresentar um diploma. De acordo com reportagem na Revista Exame de novembro de 2010, por Rogerio Jovaneli, muitas empresas valorizam mais o conhecimento e a experiência do que um diploma, um dos motivos é a dificuldade da universidade em acompanhar os avanços tecnológicos (JOVANELI, 2010).

Na percepção de CTI, não há praticamente comunicação entre os que trabalham com informática. Foi perguntado a ele se conhecia fóruns de discussão na internet sobre resolução de problemas com equipamentos ou softwares e ele concordou que esta seja uma ferramenta de comunicação. CTI menciona a SBPC, Sociedade Brasileira para o Progresso da Ciência, como um dos eventos onde se encontram profissionais da tecnologia e trabalhos acadêmicos científicos são veiculados entre os pares. A definição da comunidade discursiva revelou-se um tema que deve ser melhor aprofundado, pois não se apresenta bem delineada. 


\section{Documentos Norteadores}

As Resoluções estabelecem que a etapa da Educação Básica que se refere ao Ensino Médio deve preparar para o "trabalho e a cidadania", devendo, o aprendiz, ser capaz de continuar aprendendo, se aperfeiçoando e se adaptando às condições da profissão. A melhora da condição humana prevê a formação ética, da autonomia intelectual e do pensamento crítico. Associando a teoria e a prática no ensino e na aprendizagem, é previsto que haja a integração entre os conhecimentos gerais e entre esses e os técnico-científicos. É orientação dos textos para que haja um diálogo entre a educação e a prática social, justifica-se, então, novamente, a inserção de gêneros utilizados na situação real de trabalho no ensino.

Já o Projeto Pedagógico do Curso (PPC) traça o perfil profissional dos formandos que serão "capazes de contribuir com o desenvolvimento local e regional através da capacitação técnica especializada em desenvolvimento de softwares e manutenção de sistemas computacionais" (IFAC, 2014, p. 6), ou seja, o foco é a especificidade da formação profissional. O PPC estabelece as diretrizes gerais do curso, apresentando a matriz das disciplinas de forma que dificulta a percepção da interdisciplinaridade exigida para a proposição de articulação dos conhecimentos e da prática profissional. Não há qualquer menção específica para o ensino da língua estrangeira/inglês nesses documentos, por isso, atém-se à orientação geral de que deverá haver na "identidade" do egresso, "conhecimentos, competências e saberes profissionais requeridos pela natureza do trabalho, pelo desenvolvimento tecnológico e pelas demandas sociais, econômicas e ambientais" (BRASIL, 2012b, p. 3).

Entretanto, a ementa da disciplina, apesar de anunciar a temática "leitura de gêneros textuais na área de informática", não apresenta bibliografia compatível com a proposta de integração ou de gêneros. Prioriza o ensino de estratégias de leitura, gramática e pronúncia, desconsiderando o ensino de gêneros que seriam relevantes para a prática profissional dos aprendizes.

\section{Respostas dos professores da área técnica}

Dos sete professores abordados para responder ao questionário, dois usam materiais em inglês com frequência, um usa eventualmente e quatro usam raramente. Dessa forma, nenhum professor da área técnica disse que não utiliza inglês em suas aulas. Esse dado demonstra que deve ser aprofundada a análise para a necessidade de aprendizagem do inglês para fins acadêmicos e reforça que essa língua é a mediadora das relações sociais, comerciais e científicas na área da computação (ARANHA; VIEIRA, no prelo). Ao solicitar, na questão seguinte, para que especificassem quais materiais utilizavam, as respostas foram: websites, códigos e textos com palavras técnicas em inglês. Nota-se, pelas demandas apresentadas pelos professores para a aprendizagem dos alunos, que maior importância é atribuída ao léxico e às estratégias de leitura.

Todos os professores respondentes concordam que os alunos devem saber inglês para programar (a questão 6 questionava para que o aluno precisa de inglês no cotidiano). Seis assinalam a importância da leitura de instruções no computador e cinco a leitura de textos de disciplinas e de interesse do aluno; houve apenas três escolhas nesta questão para habilidades orais: conversar sobre a profissão e ouvir música. A ênfase maior é na leitura de textos relacionados à área de formação. Esses dados 
corroboram a opinião dos alunos com relação à importância dada ao que se refere à programação e leitura de textos de informática.

Em seguida, foi avaliada a capacidade dos alunos nas quatro habilidades, ler, escrever, ouvir e falar. Os professores diferem consideravelmente dos alunos neste ponto, pois avaliam como "muito ruim" a leitura e "nula a muito ruim" as demais habilidades. Resultado este que reforça mais uma vez a necessidade de aplicar uma avaliação das habilidades dos alunos, com base na expectativa dos professores para a comunicação acadêmica, a fim de complementar os dados. O que os alunos julgam como bom pode não ser o suficiente para o contexto acadêmico, como sugere a percepção dos professores.

A última pergunta aceitava sugestões para um possível curso de inglês que atendesse às necessidades dos aprendizes do EMII. Uma das respostas é enfática em afirmar que o conhecimento adquirido por esse professor através da leitura de textos em inglês é mais importante do que o aprendido na faculdade. O professor acredita que é urgente a integração da disciplina de inglês com a área técnica. Essa sugestão intensifica o mérito de que a disciplina precisa ajustar seu foco, pois a opinião do professor indica que ele não vê integração entre as áreas. Outra indicação interessante foi que $20 \%$ do curso fosse através do uso de "novas tecnologias como minicursos on-line, plataformas interativas, plataforma EaD". Apresentam-se, então, ferramentas compatíveis, inclusive, com a característica essencial do curso em informática.

Para esclarecer a dúvida a respeito da documentação apresentada por um Consultor Técnico, um dos professores entrevistado, afirmou que há teóricos na área de tecnologia que definem a documentação, porém, ele mesmo ficou refletindo sobre qual documentação os alunos do EMII teriam necessidade de reconhecer. Cogita-se abordar outros professores para que o levantamento da investigação sobre os gêneros na área profissional seja complementado.

\section{Respostas dos alunos ao questionário e entrevista}

O perfil dos alunos do EMII do IFAC das turmas de 2016 foi identificado através das respostas ao questionário on-line. A primeira questão do questionário identificava a turma à qual pertencia o aluno. A partir da Figura 1, percebe-se que a maioria dos discentes são do primeiro ano do curso, o que implica menos experiência com o EMI. A segunda questão se referiu à experiência de ter ou não estudado inglês antes do Ensino Médio, por ser importante considerar a experiência prévia dos aprendizes (HUTCHINSON; WATERS, 1987; ARANHA, 2009). Neste caso, apenas $27,1 \%$ assinalaram que tiveram inglês entre o $1^{\circ}$ e $6^{\circ}$ ano do Ensino Fundamental e $51,4 \%$ entre o $7^{\circ}$ e $9^{\circ}$ ano. Isso se deve à oferta exclusiva de língua espanhola em algumas escolas de Rio Branco, durante o Ensino Fundamental. 


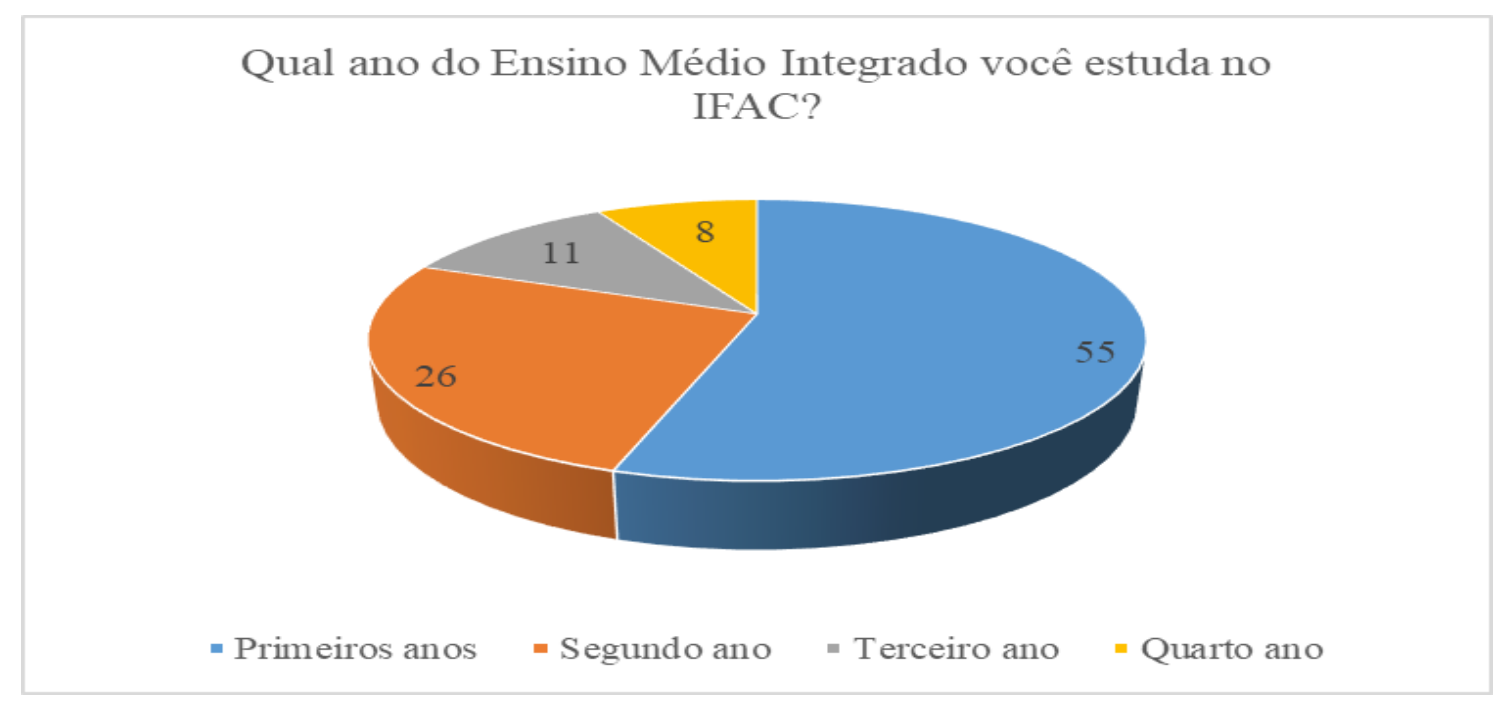

Figura 1. Quantidade de alunos por turma que respondeu ao questionário

Não mais que $10 \%$ estudou em escolas de idiomas entre 1 e 3 anos, e menos de $3 \%$ estudou mais de 3 anos. A quantidade de sujeitos que estuda sozinho é interessante $(38 \%)$, dado que pode revelar uma certa autonomia e interesse por parte desses alunos. Esse resultado identifica a diversidade das experiências prévias dos aprendizes que pode levar a níveis de conhecimentos diferentes, portanto, antes da elaboração do syllabus, no início de cada ano letivo, é essencial realizar um processo detalhado de análise da situação-presente, para que sejam identificadas as necessidades específicas de cada grupo.

Mais de 50\% deles percebem dificuldade em aprender inglês. Entretanto, mais de $60 \%$ afirmam ter relativa facilidade com a leitura de textos de informática, que são os mais requeridos pelos professores. Dessa forma, assume-se que os alunos podem perceber sua dificuldade com relação ao inglês geral, para se comunicar, escrever ou ler outros assuntos que não os de sua área de formação profissional. Esses dados reforçam que uma avaliação da situação-presente, ou seja, um diagnóstico detalhado ao início do curso, colabora para a proposição de um syllabus para a disciplina de inglês. O professor de inglês, se tiver como cerne do ensino a compreensão de gêneros da área, pode contar com entusiasmo e comprometimento dos alunos, mais do que se trabalhar com livros didáticos usuais ao Ensino Médio, uma vez que os aprendizes expressam interesse e valorizam o conhecimento específico.

Ao indagar, na quarta questão, a respeito de como se sentiam durante as aulas de inglês onde estudaram, se tinham hábito de estudo em casa e quais os tipos de atividades que gostavam ou não, foram revelados os sentimentos dos alunos nas aulas e seus desejos. Como a questão não foi marcada como obrigatória, apenas 48 alunos responderam; desses, 13 afirmaram que se sentiam "bem" nas aulas, no entanto, dez respostas, representando $10 \%$ do total, expressam sentimentos negativos ou apatia com relação à aprendizagem ou ao conforto com as atividades em sala de aula. É importante considerar a probabilidade de outros alunos terem tido experiências ruins com a aprendizagem de inglês, por isso o professor deverá estar preparado para prováveis atitudes ou posturas de rejeição de alguns adolescentes. 
Hutchinson e Waters (1987) chamam a atenção para o fato de que os aprendizes são seres humanos, portanto, possuem apreços e desprazeres, medos, fraquezas e preconceitos. Aprendizes são pessoas e a aprendizagem de uma língua, em particular, é uma experiência emocional, por isso os sentimentos gerados durante o processo de aprendizagem são determinantes para o sucesso ou o fracasso. Há, então, que se dar a devida importância aos sentimentos dos alunos no decorrer do processo de aprendizagem. Os alunos que expressaram se sentir nervosos, com dificuldade ou falta de interesse em suas experiências anteriores com a aprendizagem do inglês podem nos alertar para uma provável falta de motivação ou expectativa ruim com relação às aulas. Estar preparado para uma situação de resistência pode evitar que haja influência e disseminação do mal-estar para outros colegas de classe.

Entre as atividades preferidas dos aprendizes estão a música e as atividades orais, mencionam também eventos, feiras, gincanas, dinâmicas. Assim, considera-se o estudo de metodologias que o professor possa contribuir para instigar o interesse, o dinamismo, e ao mesmo tempo desenvolver uma postura que seja investigativa e crítica, pois deve ser assumido o trabalho como princípio educativo, integrando-o à ciência, cultura e tecnologia (BRASIL, 2012b). As atividades lúdicas precisam ser bem pensadas e elaboradas para que garantam a produção de conhecimento, a integração dos saberes e a preparação para os desafios do mundo do trabalho.

A questão 5 se referia ao uso da língua no cotidiano, servindo para o levantamento da consciência da necessidade da língua para o aluno e também preparando para a próxima pergunta que levantava quais atividades eram usadas no cotidiano em inglês. Um total de $66 \%$ dos alunos afirma ter contato com o inglês no seu cotidiano, 34\% não, porém, 28 alunos desses 34 responderam à próxima questão, a qual se refere às atividades no cotidiano que ele/ela usa o idioma, ou seja, somente respondeu à $6^{\mathrm{a}}$ questão quem utiliza de alguma forma a língua. Esse fato leva a reconsiderar a porcentagem dos que têm contato com o inglês, sendo, na verdade, um total de $94 \%$. Em aproximadamente $45 \%$ das respostas à $6^{\mathrm{a}}$ questão, a informação é de que os alunos utilizam inglês para ler textos sugeridos pelos professores das disciplinas atuais, ler textos na internet, ler instruções no computador e programar. Apresenta-se, a partir dessas respostas, um forte viés para a leitura de textos específicos da área profissional e a compreensão de vocabulário técnico. A necessidade de vocabulário é também enfatizada por professores da área técnica quando em momentos de reuniões de planejamento com todas as disciplinas, por exemplo. Deve-se verificar, entretanto, uma metodologia de trabalho com o vocabulário que não se limite à apreensão de palavras descontextualizadas.

Uma parcela de $75 \%$ dos alunos ouve músicas em inglês. Os professores, da mesma forma, valorizam a compreensão de músicas. Hutchinson e Waters (1987) afirmam que as percepções dos alunos diante das suas necessidades podem diferir da percepção do professor de IFE e da instituição, mas alertam que o desejo do aluno não deve ser desconsiderado em favor da motivação. O favoritismo por músicas nas aulas é um dado que chama a atenção, não se relaciona diretamente com o fim específico da formação profissional. No entanto, uma pesquisa sobre como pode ser utilizada a música é requerida, pois pode contribuir para a motivação dos alunos com a aprendizagem. 
Para se obter uma ideia da situação-presente, os alunos auto avaliaram suas capacidades de leitura, escrita, compreensão auditiva e fala (Figura 2). A partir da consciência de seus conhecimentos e de suas dificuldades, o aprendiz adquire maior autonomia para aprender e mais clareza de suas necessidades. No geral, os respondentes avaliam suas capacidades como nulas a medianas, de 0 a 3 na questão 7 , e mais da metade $(53 \%)$ considera que possui dificuldades para aprender o inglês, conforme resposta à questão 8 . Essa $8^{\mathrm{a}}$ questão preparava para a autoavaliação, na questão seguinte, através de perguntas sobre o grau de dificuldade em cada atividade relacionada a uma habilidade apresentada. Na habilidade mais requerida na questão 6, qual seja, a de ler textos em informática, os alunos que afirmam ter facilidade entre 0 a 3 representam $61 \%$; contrastando com textos de outros assuntos, essa porcentagem cai para $49 \%$. Apesar de a maioria considerar que tem dificuldades com a aprendizagem e com as habilidades, a leitura de textos da área parece ser mais tranquila para mais de $60 \%$, isso leva a considerar que o conhecimento dos alunos na área profissional é relevante. Em razão disso, o trabalho com os gêneros específicos da área, conforme se sugere, deve oferecer algum grau de desafio compatível, garantindo a motivação e a aprendizagem de algo novo.

De 0 a 5, como você avalia sua capacidade de:

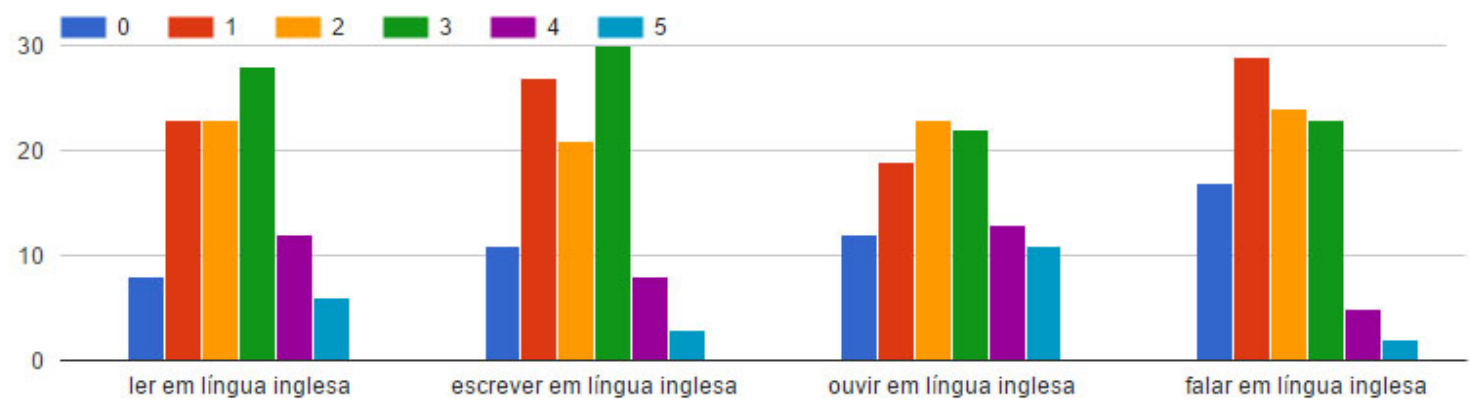

Figura 2. Auto avaliação das habilidades de leitura, escrita, compreensão auditiva e fala

Fonte: Elaboração própria

$\mathrm{Na}$ questão $10,83 \%$ assinala que o inglês é necessário para viajar ao exterior. Acredita-se que essas respostas não foram feitas levando-se em conta a própria necessidade, logo, é preciso reavaliar a pergunta para esclarecê-la. Ainda assim, 64\% apontam para a importância de ler textos em inglês, compreender comandos e instruções no computador e trabalhar. $\mathrm{O}$ foco dos alunos é no desempenho das tarefas no trabalho, o que equivale à importância dada pelos professores. A diferença é a necessidade de fazer prova do ENEM (Exame Nacional do Ensino Médio), com menos de 50\% de respostas que a assinalaram, pois muitos alunos escolhem a opção do espanhol para esse exame. Esse resultado reforça a necessidade de se trabalhar o inglês para o fim específico do desempenho das funções no trabalho. Porém, sem deixar de lado a compreensão de textos que incentivem o contato com questões políticas, sociais, históricas e culturais subjacentes ao mundo do trabalho. 
Nas questões seguintes, os aprendizes deram sua opinião sobre a importância do que se deve saber para conseguir desempenhar as tarefas mencionadas na questão anterior e auto avaliaram suas capacidades e conhecimentos. Dão muito valor a conhecer muitas palavras, saber pronúncia, entender uma palavra pelo contexto e conseguir entender uma informação no texto sem conhecer todas as palavras. Novamente se reforça o vocabulário e a compreensão de textos.

Foram realizadas entrevistas com grupos de alunos para verificar o conhecimento da documentação apresentada pelos informantes especialistas. Foi identificado que os alunos não conhecem essa denominação, portanto, torna-se imprescindível aprofundar o conhecimento sobre esses prováveis gêneros que poderão compor o syllabus de um curso de inglês para o EMII.

\section{Conclusão}

A Análise de Necessidades, realizada para identificar o perfil dos alunos do Ensino Médio Integrado em Informática do Instituto Federal do Acre e definir a situação-alvo para o ensino de língua estrangeira-inglês, levantou dados importantes para esclarecer qual deve ser o foco da disciplina de inglês nesse contexto e definir os próximos passos para a pesquisa.

Os documentos norteadores nacionais e locais direcionam o ensino e a aprendizagem no contexto do EMI para a formação para o trabalho, de forma que o aprendiz seja capaz de agir social, histórica e politicamente no seu ambiente, um ser humano preparado para exercer a cidadania e o pensamento crítico.

Foram consultados especialistas da área de informática que atestaram o uso frequente do inglês na rotina do programador, reforçando a necessidade de preparação para o trabalho durante a formação integrada. A partir de exemplos fornecidos pelos especialistas, chegou-se a um possível gênero que deverá ser identificado e analisado em pesquisa posterior, e que está dentro do que é denominado de documentação na área.

O ensino da língua estrangeira deve possibilitar uma integração, uma maior aproximação entre o ensino e a prática social de forma a desenvolver as capacidades requeridas pelo mundo do trabalho. Alunos e professores concordam que o inglês é muito importante na formação do profissional de informática, na compreensão de textos da área e de vocabulário técnico para programar. Os professores valorizam, ainda, textos jornalísticos, que podem propiciar o debate sobre temas diversos que contribuem para o desenvolvimento da autonomia e do pensamento crítico.

No entanto, é preciso aprofundar a compreensão de como a disciplina de inglês pode melhorar o desempenho dos alunos nas aulas das disciplinas que demandam conhecimento da língua para a leitura e a programação. $\mathrm{O}$ vocabulário e a gramática deverão ser trabalhados dentro de uma abordagem que considere os aspectos linguísticos em relação a uma estrutura retórica. É necessário aliar o conhecimento técnico com a formação cidadã e crítica, desenvolvendo a capacidade de agir com autonomia e reflexão, transformando seu ambiente. 


\section{REFERÊNCIAS}

ARANHA, S. The Development of a Genre-Based Writing Course for Graduate Students in Two Fields. In: BAZERMAN, C.; BONINI, A.; FIGUEIREDO, D. Genre in a changing world. Colorado: The WAC Clearinghouse and Parlor Press, 2009.

ARANHA, S.; VIEIRA, B. G. A. M. Conhecimento de língua, gênero e registro acadêmicos em foco: atividades na Análise de Necessidades de um curso de EAP para pós-graduandos em Ciência da Computação. In: FERREIRA, M. M.; STELLA, V. C. R. (Org.). Redação Acadêmica: múltiplos olhares para a produção textual e o seu ensino: São Paulo: Cortez, 2018. (No prelo)

BARWARSHI, A. S.; JO REIFF, M. Gênero: História, Teoria, Pesquisa e Ensino. Tradução de Benedito Gomes Bezerra. São Paulo: Parábola Editorial, 2013.

BRASIL, Presidente Lula entrega campi de universidades e institutos federais. MEC, $2010 . \quad$ Disponível em: $<$ http://portal.mec.gov.br/component/content/article?id=16096:presidente-lula-entregacampi-de-universidades-e-institutos-federais $>$. Acesso em: 05 jun. 2016.

- Ministério da Educação. Conselho Nacional de Educação. Parecer $n^{o} 11$ de 2012, sobre as Diretrizes Curriculares Nacionais para a Educação Profissional Técnica de Nível Médio, 2012a.

Ministério da Educação. Conselho Nacional de Educação. Resolução $n^{\circ} 06$, de 20 de setembro de 2012, que define as Diretrizes Curriculares Nacionais para a Educação Profissional Técnica de Nível Médio, 2012b.

BROOKSHEAR, J. G. Ciência da Computação: uma visão abrangente. 11. ed. Porto Alegre: Brookman Editora Ltda., 2013.

CERVO, A. L.; BERVIAN, P. A. Metodologia científica. 5. ed. São Paulo: Prentice Hall. 2002.

DUDLEY-EVANS, T.; St. JOHN, M. J. Developments in English for Specific Purposes: A Multidisciplinary Approach. Cambridge: Cambridge University Press, 1998.

FRIGOTTO, G.; CIAVATTA, M.; RAMOS, M. (Orgs.). Ensino médio integrado: concepção e contradições. São Paulo: Cortez, 2012.

HAQUE, N. A brief study on needs analysis. Express, an International Journal of Multi Disciplinary Research, v. 1, Issue 1, jan. 2014. Disponível em: <www.expressjournal.com>. Acesso em: 05 jun. 2016.

HEMAIS, B.; BIASI-RODRIGUES, B. A proposta sociorretórica de John M. Swales para o estudo de gêneros textuais. In. MEURER, J. L.; BONINI, A.; MOTTA-ROTH, D. (Org.). Gêneros: teorias, métodos, debates. São Paulo: Parábola Editorial, 2005. p. $108-129$.

HUTCHINSON, T.; WATERS, A. English for Specific Purposes. 14. ed. Cambridge: Cambridge University Press., 2000[1987].

IFAC (Instituto Federal do Acre). Projeto Pedagógico do Curso Técnico de Nível Médio em Informática. Acre, Rio Branco, 2014. 
JORDAN, R. R. English for Academic Purposes: A guide and resource book for teachers. Cambridge: Cambridge University Press., 1997.

JOVANELI, R. Cresce contratação de profissionais sem diploma na área de TI. Revista Exame, 2010. Disponível em: $<$ https://exame.abril.com.br/carreira/cresce-contratacaode-profissionais-sem-diploma-na-area-de-ti/>. Acesso em: 05 jun. 2016.

RAMOS, R. C. G. Gêneros Textuais: uma proposta de aplicação em cursos de inglês para fins específicos. The ESPecialist, v. 25, n. 2, p. 107-129, 2004.

ROSSINI, A. M. Z. P.; BELMONTE, J. Panorama do ensino-aprendizagem de línguas para fins específicos: histórico, mitos e tendências. Cap. 15. In: LIMA-LOPES, R. E. de.; FISCHER, C. R.; GAZOTTI-VALliM, M. A. (Orgs.). Perspectivas em Línguas para Fins Especificos: Festschrift para Rosinda Ramos. Coleção: Novas Perspectivas em Linguística Aplicada, v. 41. Campinas: Pontes Editores, 2015.

SWALES, J. M. Genre Analysis: English in academic and research settings. Cambridge: Cambridge University Press, 1990.

. Research Genres. Cambridge: Cambridge University Press, 2004.

VIEIRA, B. G. A. M.; ARANHA, S. A análise de necessidades na trajetória da elaboração de um curso de EAP para pós-graduandos em ciência da computação. The ESPecialist, v. 36, n. 1, p. 49-72, 2015.

ZOLIN-VESZ, F; SOUZA, V. G. A concepção do ensino médio integrado e o ensino crítico de línguas estrangeiras: convergências e aproximações. Revista Pesquisas em Discurso Pedagógico, Departamento de Letras-IPEL/PUC-Rio, Fascículo, 8, 2010.

Recebido em: 02/10/2017

Aprovado em: 07/12/2017 